Although the suicide rate was high among men who had reported using narcotics more than 50 times, this variable was not a significant predictor in the Cox analysis, probably because few conscripts reported such heavy use. Yet the highest suicide rate (30/1000) was found among men who reported intravenous drug use. Similarly, alcohol use was associated with a high risk of suicide only among heavy drinkers-that is, those who drank spirits several times a week (table I).

In several recent articles the possibility of predicting suicide in patients with psychiatric illness has been discussed. ${ }^{22-24}$ Pokorny concluded from a prospective study of 4800 such patients that the low sensitivity and specificity of risk factors and the low base rate of suicide made it impossible to predict suicide in individual cases. ${ }^{22}$ Motto et al took a more optimistic view and developed a clinical instrument to estimate the risk of suicide based on a follow up of 2753 patients with psychiatric disease, although they pointed out its limitations. ${ }^{23}$ Prediction of suicide in individual cases is even less feasible in an unselected population of conscripts as the base rate of suicide is much lower than that among patients with psychiatric illness. ${ }^{2+25}$ Thus our findings cannot be used to create an instrument to screen men at conscription.

Preventing suicide in individual cases is most effective in settings in which the associated risk factors are frequent. Thus people at risk tend to be seen by the social services, in treatment programmes for substance abuse, and in delinquency units. Knowledge of the predictors of suicide within these units may facilitate identification of those at risk and intervention. Future research should focus on markers of antisocial traits conducive to suicide in young men.

The study was supported by a grant from the Swedish Medical Research Council, No B88-27X-08322-01. We acknowledge the help of Per Näsman with the computer programming.
1 Wall S, Rosén M, Nyström L. The Swedish mortality pattern: a basis for health planning. In 7 Epidemiol 1985;14:285-92.

2 Murphy GR, Wetzel RD. Suicide risk by birth cohort in the United States 1949 to 1974. Arch Gen Psychiatry 1980;37:519-23.

3 Solomon MI, Hellon CP. Suicide and age in Alberta, Canada, 1951 to 1977. Arch Gen Psychiaty 1980;37:511-3.

4 Goldney RD, Katsikis M. Cohort analysis of suicide rates in Australia. Arch Gen Psychiatry 1983;40:71-4.

5 Nordström P, Åsgărd U. Suicide risk by age and birth cohort in Sweden. Crisis 1986;7:75-80.

6 Otto U. Function of male youths during military service. Acta Psychiatr Scand [Suppl] 1980;282:1-59.

7 Barraclough BM. Differences between national suicide rates. $\mathrm{Br} f$ Psychiatry 1973;122:95-6

8 Bolander A-M, Ettlinger R. Suicide in Sweden. In: Health and societv. V. Different aspects of mortality in Sweden. Stockholm: Committee for Future Different aspects of mortality in Sweden. Stockholm: Comm

9 Cox DR. Regression models and life tables. Fournal of the Royal Statistical Society 1972;343:187-200.

10 Allgulander C, Fisher LD. Survival analysis (or time to an event analysis) and the Cox regression model-methods for longitudinal psychiatric research. Acta Psychiatr Scand 1986;74:529-35.

11 Benson G, Holmberg MB. Validity of questionnaires in population studies on drug use. Acta Psychiatr Scand 1985;71:9-18.

12 Angst J, Clayton P. Premorbid personality of depressive, bipolar, and schizophrenic patients with special reference to suicidal issues. Comp Psychiatry 1986;27:511-32.

13 Ruppen R, Müller U, Baumann U, Angst J. Zur Prüfung der Aussagegenauigkeit bei einer Befragung über Drogenkonsum. Zeitschrift für Präventivmedizin 1973:18:173-81.

14 Rich CL, Young D, Fowler RC. San Diego suicide study. I. Young vs old subjects. Arch Gen Psychiatry 1986;43:577-82.

15 Shafii M, Carrigan S, Whittinghill JR, Derrick A. Psychological autopsy of completed suicide in children and adolescents. Am F Psychiatry 1985;142: $1061-4$

16 Otto U. Suicidal acts by children and adolescents. Acta Psychiatr Scand [Suppl] 1972;233:1-123.

17 Paffenbarger RS, Asnes AP. Chronic disease in former college students. III. Precursors of suicide in early and middle life. Am $\mathcal{J}$ Public Healt 1966;56: 1026-36

18 Hendin H. Suicide: a review of new directions in research. Hosp Community Psychiatry 1986;37:148-54.

19 Hawton K. Assessment of suicide risk. Br f Psychiatry 1987; 150:145-53.

20 Brown GL, Goodwin FK. Human aggression and suicide. Suicide Life-Threat Behav 1986;1:223-39.

21 Åsberg M. Biochemical aspects of suicide. Clin Neuropharmacol 1986;9(suppl 4):374-6.

22 Pokorny AD. Prediction of suicide in psychiatric patients. Arch Gen Psychiatry 1983;40:249-57.

23 Motto JA, Heilbron DL, Juster RP. Development of a clinical instrument to estimate suicide risk. Am $\mathcal{F}$ Psychiatry 1985;142:680-6.

24 Murphy GE. On suicide prediction and prevention. Arch Gen Psychiatry 1983;40:343-4.

25 Galen RS, Gambino SR. Beyond normality: the predictive value and efficiency of medical diagnoses. New York: John Wiley and Sons, 1975.

(Accepted 12 April 1988)
Department of

Microbiology,

Wythenshawe Hospital,

Manchester M23 9LT

Barbara J Isalska, MB, senior registrar

T N Stanbridge, FRCPATH, consultant microbiologist

Correspondence to: Dr Isalska.

\section{Fluconazole in the treatment of candidal prosthetic valve endocarditis}

\author{
Barbara J Isalska, T N Stanbridge
}

We report the first use of fluconazole in the treatment of prosthetic valve endocarditis due to Candida parapsilosis.

\section{Case report}

A 37 year old woman presented with a six week history of anorexia with nausea, weight loss, fever, sweats, and rigors. Sixteen weeks earlier, because of failure of a xenograft inserted eight years previously, she had undergone mitral valve re-replacement with a Starr-Edwards valve. Culture of the excised valve yielded a growth of Staphylococcus albus, which was considered to be a contaminant, from fluid medium only. Convalescence was complicated by a serous discharge from the wound in the groin through which cardiac bypass had been established. The exudate was not cultured.

On examination she was feverish $\left(38.5^{\circ} \mathrm{C}\right)$ and sweating but not in cardiac failure. There were no other features of endocarditis. Haemoglobin concentration was $114 \mathrm{~g} / \mathrm{l}$, white cell count $6 \cdot 7 \times 10^{9} / 1$, and erythrocyte sedimentation rate $35 \mathrm{~mm}$ in the first hour. Serum creatinine and liver function values were normal and repeated echocardiograms were noncontributory. Five separate blood cultures yielded $C$ parapsilosis. Further surgery was judged to be unacceptably hazardous and she was treated with a total of $2.05 \mathrm{~g}$ amphotericin B. Six blood cultures over the next two months grew no pathogens.

Six months later the patient was readmitted with a four day history of myalgia, headache, and fever and had developed a mitral regurgitant murmur. $C$ parapsilosis was isolated from five of six blood cultures. Treatment with flucytosine and amphotericin B was begun but replacement of the infected valve was again considered to be unacceptably hazardous. Investigations failed to identify any other focus of fungal infection, and because of deteriorating renal function alternative antifungal treatment was sought.

Oral treatment with $200 \mathrm{mg}$ fluconazole daily was instituted and the prothrombin time closely monitored because of concomitant treatment with nicoumalone. Five days later, however, she suffered an intracranial haemorrhage (prothrombin time $170 \mathrm{~s}$; control $15 \mathrm{~s}$ ). A computed tomogram showed a $4 \mathrm{~cm}$ space occupying lesion with a density of blood in the upper left parietal region, and histological examination and culture of the surgically evacuated clot failed to detect the presence of fungi. Owing to deteriorating renal function the fluconazole was reduced to $100 \mathrm{mg} / \mathrm{day}$ and she continued with this dose, though her renal function subsequently improved (figure). Twelve sets of blood 


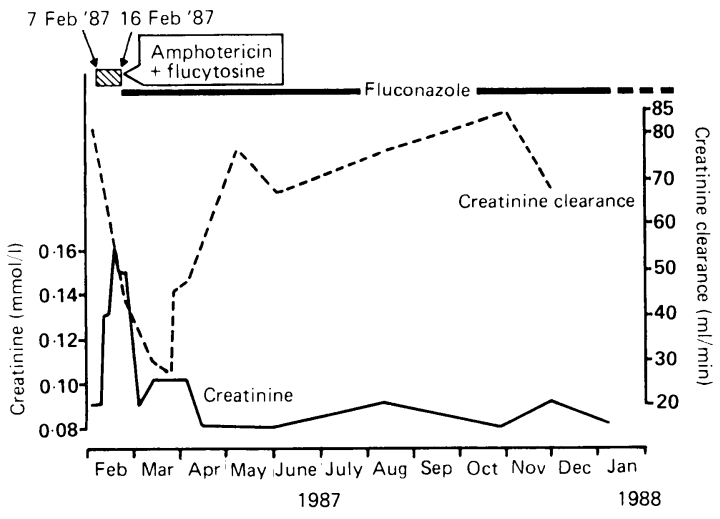

Indicators of renal function during management of relapsed episode of prosthetic valve endocarditis

samples cultured at intervals over the next year grew no pathogens.

\section{Comment}

Reviews of candidal endocarditis have noted the high mortality from the condition. ${ }^{12}$ Survival without surgical intervention is almost unknown and most authorities recommend early replacement of the infected prosthesis. The mainstay of antifungal treatment is amphotericin B, which penetrates poorly into fungal vegetations." Prolonged use of this nephrotoxic drug compounds the problems of possible glomerulonephritis and the use of potent diuretics.

The decision to use fluconazole was based on available evidence that, though the drug is fungistatic and appears to offer no advantage over some other oral agents containing azole in vitro, ${ }^{4}$ it is reportedly more active than ketoconazole in vivo. ${ }^{5}$ Treatment of the infection in our patient was complicated by cerebral haemorrhage. As there was no evidence of a mycotic aneurysm the cerebral haemorrhage may have resulted from interaction between the anticoagulant and fluconazole, as nicoumalone is metabolised by cytochrome $P-450$ enzymes, which may be inhibited by fluconazole.

The duration of fluconazole treatment was a matter of conjecture. We did not think that serological studies would help in that respect and, though there was no evidence of drug toxicity and renal and liver function values remained normal, we thought it prudent to continue with a maintenance dose for at least the foreseeable future and possibly for life.

We thank Dr C L Bray and Mr R A M Lawson for permission to report this case.

1 Rubinstein E, Noriega ER, Simberkoff MS, et al. Fungal endocarditis: analysis of 24 cases and review of the literature. Medicine (Baltimore) 1975;54:331-44. Seelig MS, Speth CP, Kozinn PJ, et al. Patterns of candida endocarditis following cardiac surgery: importance of early diagnosis and therapy (an
forlis following cardiac surgery: importance of early diagnosis

3 Rubinstein E, Noriega ER, Simberkoff MS, et al. Tissue penetration of amphotericin $B$ in candida endocarditis. Chest 1974;66:376-7.

4 Odds $\mathrm{FC}$, Cheesman SL, Abbott AB. Antifungal effects of fluconazole (UK 49858), a new triazole antifungal, in vitro. J Antimicrob Chemother 1986;18: $473-8$

5 Rogers TE, Galgiani JN. Activity of fluconazole (UK 49,858) and ketoconazole against Candida albicans in vitro and in vivo. Antimicrob Agents Chemother 1986;30:418-22.

Accepted 10 May 1988)

\section{Thromboses and thromboemboli in patients with lymphoma during cytotoxic chemotherapy}

\author{
Brian M J Cantwell, James Carmichael, \\ Sarah E Ghani, Adrian L Harris
}

University Department of Clinical Oncology, Newcastle General Hospital, Newcastle upon Tyne NE46BE Brian M J Cantwell, MD, senior lecturer

James Carmichael, MD, lecturer

Sarah E Ghani, BA, data manager

Adrian L Harris, DPHIL, professor

Correspondence to:

Dr Cantwell.
Deep venous thromboses cause appreciable morbidity and are potentially fatal. Sixty per cent of deaths due to pulmonary emboli occur in patients in whom such a diagnosis was not suspected.' Most patients will survive if treated with anticoagulant drugs, and the long term prognosis is good, with an overall rate of recurrence of emboli of about $10 \%$, which is lower if a reversible precipitating cause is present.'

We report on two patients with pulmonary emboli and three others with deep venous thromboses that developed during cytotoxic chemotherapy for malignant lymphomas.

\section{Patients, methods, and results}

We examined the records of 49 consecutive patients in whom malignant lymphoma had been recently diagnosed. Five patients with stage 1 non-Hodgkin's lymphoma were treated by radiotherapy alone. Combination chemotherapies for 12 patients with Hodgkin's lymphoma and six with non-Hodgkin's lymphoma were vinblastine $6 \mathrm{mg} / \mathrm{m}^{2}$ intravenously on days 1 and 8 and procarbazine $150 \mathrm{mg}$, chlorambucil $6 \mathrm{mg} / \mathrm{m}^{2}$, and prednisolone $40 \mathrm{mg}$ all given orally each day for 14 days. Cycles were repeated every 28 days. In a subgroup of patients this combination of chemotherapy was alternated with doxorubicin $25 \mathrm{mg} / \mathrm{m}^{2}$, bleomycin $10 \mathrm{mg} / \mathrm{m}^{2}$, dacarbazine $375 \mathrm{mg} / \mathrm{m}^{2}$, and vincristine $2 \mathrm{mg}$ given intravenously on days 1 and 15 . Seventeen patients with high grade non-Hodgkin's lymphoma were given cyclophosphamide $750 \mathrm{mg} / \mathrm{m}^{2}$, doxorubicin $40 \mathrm{mg} / \mathrm{m}^{2}$, vincristine $2 \mathrm{mg}$, and bleomycin $10 \mathrm{mg}$ intravenously on day 1 ; prednisolone $40 \mathrm{mg}$ orally on days $1-5$; and methotrexate $200 \mathrm{mg} / \mathrm{m}^{2}$ intravenously on day 15 with folinic acid on day 16 . Cycles were repeated every 21 days. Nine patients with intermediate or low grade non-Hodgkin's lymphoma were given chlorambucil $10 \mathrm{mg}$ and prednisolone $40 \mathrm{mg}$ orally each day for 10 days with vincristine $2 \mathrm{mg}$ intravenously on day 1 . Cycles were repeated every 21 days.

The five patients who developed thromboses or thromboemboli did so after starting combination chemotherapy, to which they all responded. The table shows their clinical details. The thromboses and thromboemboli developed quickly (median 4 weeks, range 2-15 weeks) and resolved rapidly with intra-

Characteristics of patients with deep venous thromboses or pulmonary emboli

\begin{tabular}{|c|c|c|c|c|c|c|}
\hline Case No & Age (years) & Sex & Lymphoma type & Vascular events & Site of lymphoma & Chemotherapy \\
\hline 1 & 59 & M & Non-Hodgkin's & Multiple pulmonary emboli & Mediastinum & Chlorambucil, prednisolone, vincristine \\
\hline 2 & 54 & $\mathrm{~F}$ & Non-Hodgkin's & Multiple pulmonary emboli & Lung, peri-renal & Vinblastine, procarbazine, chlorambucil, prednisolone \\
\hline 3 & 52 & M & Non-Hodgkin's & Leg deep vein thrombosis & Mediastinum & $\begin{array}{l}\text { Cyclophosphamide, doxorubicin, vincristine, bleomycin, prednisolone, } \\
\text { methotrexate, folinic acid }\end{array}$ \\
\hline 4 & 38 & $\mathrm{~F}$ & Hodgkin's & Axillary vein thrombosis & Mediastinum, spleen, liver & Vinblastine, procarbazine, chlorambucil, prednisolone \\
\hline 5 & 26 & $\mathrm{~F}$ & Hodgkin's & Axillary vein thrombosis & Lung & Vinblastine, procarbazine, chlorambucil, prednisolone \\
\hline
\end{tabular}

